\title{
Funcionalista, determinista e reducionista: 0 feminismo da reprodução social e seus críticos ${ }^{1}$
}

\author{
Cinzia Arruzza ${ }^{2}$
}

Resumo: A noção de reprodução social articulada pelo feminismo marxista, no interior de uma teoria unitária da opressão de gênero e do capitalismo, foi acusada no passado de ser ou funcionalista ou econômica e biologicamente determinista. Essas acusações baseiam-se em uma incompreensão fundamental das noções marxistas de produção e de reprodução e de um entendimento reificado do que a sociedade capitalista é. Ademais, frequentemente aquelas que criticaram a compreensão feminista marxista de reprodução social não foram capazes de oferecer uma alternativa sólida e acabaram em impasses teóricos ainda maiores, particularmente exemplificados pelas teorias dos sistemas duplos e triplos. No sentido contrário, a noção de reprodução social tem o potencial de evitar esses impasses, enquanto concomitantemente sugere uma perspectiva não-reducionista do modo capitalista de produção: aquele no qual o capital não é considerado como o sujeito de um processo estritamente "econômico".

Palavras-chave: Teoria da reprodução social; Consubstancialidade; Marxismo.

\footnotetext{
${ }_{1}$ Em versão estendida, este artigo foi publicado originalmente em Science and Society, vol. 80, n. 1, Janeiro de 2016. A adequação do texto para o Cadernos Cemarx foi feita pela própria autora. Tradução: Murillo van der Laan. Revisão: Mariana Shinohara Roncato e Rafael Dias Toitio.

2 Professora associada da New School for Social Research, Nova York. E-mail: arruzzac@newschool.edu. Este artigo foi apresentado no workshop “Crisis, Critique, Capitalism", organizado por Nancy Fraser, e realizado entre 21 e 23 de novembro de 2013, na Maison Suger, em Paris. Gostaria de expressar minha gratidão a ela e a todos os participantes pelos interessantes comentários. Sou grata também a Johanna Brenner, Nancy Holmstrom, Sue Ferguson e Felice Mometti por suas considerações em versões anteriores desse texto, e à Jeffery Webber por me convidar para apresenta-lo na Queen Mary University, de Londres. Agradeço também aos meus alunos Marcello Kilani e Juniper Alcorn pelas adequações ao inglês.
} 


\begin{abstract}
The notion of social reproduction articulated by Marxist feminists within a unitary theory of gender oppression and capitalism has been accused in the past of being either functionalist or economic and biological determinist. These accusations were based on a fundamental misunderstanding of the Marxist notions of production and reproduction and on a reified understanding of what a capitalist society is. Moreover, often those who have criticized the Marxist feminist understanding of social reproduction have not been able to offer a solid alternative and have ended up in even greater theoretical impasses, particularly exemplified by dual and triple systems theories. On the contrary, the notion of social reproduction has the potential to avoid these impasses, while at the same time suggesting a non-reductionist account of the capitalist mode of production: one in which capital is not seen as the subject of a strictly "economic" process. Keywords: Social Reproduction Theory; Consubstantiality; Marxism.
\end{abstract}

\title{
Introdução
}

A noção de reprodução social, introduzida ao debate pelas feministas marxistas e socialistas há mais de três décadas, tinha a intenção de oferecer uma análise sofisticada e não-reducionista da relação entre opressão de gênero e capitalismo, sem cair no impasse de teorias dos sistemas duplos ou triplos. As feministas marxistas destacaram o fato de que um modo de produção e uma certa estrutura de relações de classe definem o quadro no interior do qual os processos de reprodução social, i. e., os processos de reprodução e manutenção da vida humana, ocorrem (FERGUSON, 1999). Johanna Brenner e Barbara Laslett (1991, p. 314) sugeriram uma distinção terminológica entre reprodução societal e reprodução social. Enquanto a reprodução societal indica a reprodução de um sistema inteiro de relações sociais, a reprodução social refere-se ao domínio mais específico da renovação e da manutenção da vida e das instituições e o trabalho necessário aí envolvido. Isso deve ser entendido como abrangendo três elementos fundamentais: "a reprodução biológica da espécie",

\begin{tabular}{l|l}
\hline 40 & Funcionalista, determinista e reducionista:...
\end{tabular} 
"a reprodução da força de trabalho" e a "reprodução das necessidades de aprovisionamento e de cuidado" (BAKKER e GILL, 2003, p. 32). $\mathrm{Na}$ definição de Brenner e de Laslett, a reprodução societal inclui a reprodução social: isto significa que relações específicas de classe também definem o quadro dentro do qual a reprodução social ocorre. A noção de reprodução social, nessa perspectiva, tem o sentido de destacar a centralidade do trabalho de manutenção da vida e de reprodução da próxima geração como uma parte do trabalho necessário no interior de todo o processo de reprodução societal. Sob o capitalismo a maior parte desse trabalho é executado no interior da unidade familiar, mas esse não é necessariamente sempre o caso. Ademais, dentro do capitalismo, a porção desse trabalho que é executada seja no interior da família, seja pelo Estado na forma de bem-estar, ou pelo mercado, varia de acordo com as circunstâncias históricas específicas (BRENNER e LASLETT, 1989, p. 383-384).

Já há algumas décadas atrás, Lise Vogel (1983) identificou a noção de reprodução social como a base para uma teoria unitária da opressão de gênero e sua relação com o capitalismo, que fosse capaz de evitar as armadilhas dos dualismos, uma vez que esses nada fazem além de postergar o problema - ao invés de resolvê-lo - de se ter uma compreensão explicativa das desigualdades de gênero. Este artigo tem a intenção de contribuir teoricamente com o renascimento que a noção de reprodução social experimentou na última década (FERGUSON, 1999 e 2008; BAKKER e GILL, 2003; KATZ, 2004; BEZANSON e LUXTON, 2006). Para reavaliar a noção de reprodução social dentro do quadro de uma teoria unitária da opressão de gênero e do capitalismo abordarei, em primeiro lugar, os limites das noções de interação de diferentes sistemas de relações sociais (classe, gênero e raça), que reproduzem como o feminismo materialista, por exemplo - as limitações das teorias de sistemas duplos ou triplos. Irei abordar, então, algumas das críticas avançadas contra a noção de reprodução social que tem sido articulada pelas feministas marxistas no interior da perspectiva de uma teoria unitária. Meu objetivo é demonstrar que as acusações de determinismo 
biológico e econômico, e de funcionalismo, estão baseadas em uma interpretação equivocada das noções de produção e reprodução da perspectiva marxista.

\section{Interação e "consubstancialidade"}

O feminismo marxista nunca teve uma vida fácil. Tem estado sob a pressão tanto das críticas ao marxismo por parte das feministas radicais e das feministas pós-estruturalistas, quanto daquela advinda do atraso dos teóricos marxistas em dar a devida atenção à questão da relação entre gênero e capitalismo, e de fornecerem repostas convincentes à tal questão. A despeito de prosperar por um curto período, entre fins dos anos 1960 e 1970, o feminismo marxista, não obstante, passou por uma grande crise nos anos 1980, sob a pressão da literatura feminista que se desenvolveu, em grande medida, em antagonismo a uma "caricatura de Marx", caracterizada por um determinismo, um materialismo vulgar, categorias cegas ao sexo, e por um reducionismo econômico (GIMENEZ, 2005, p. 11). A adoção na literatura feminista socialista de teorias de sistemas duplos ${ }^{3}$, e depois triplos, que em suas várias formas e derivações ainda influencia fortemente uma porção significativa da literatura feminista materialista atual, não ajudou a confrontar e revisar de maneira adequada a teoria marxista tradicional ${ }^{4}$. Como Iris Marion Young (1997) observou,

\footnotetext{
${ }^{3}$ Heidi Hartmann (1981) foi a primeira a teorizar sobre as teorias de sistemas duplo, em seu famoso artigo "The Unhappy Marriage of Marxism and Feminism: Towards a More Progressive Union". A afirmação básica do artigo era que o patriarcado e o capitalismo são dois sistemas relativamente autônomos, que interagem um com o outro, fortalecendo-se reciprocamente. Essa teoria foi corrigida posteriormente - por Sasha Roseneil (1994) e Sylvia Walby (1990), por exemplo -, pela teoria dos sistemas triplos, que inclui o racismo como um sistema próprio.

${ }^{4}$ As designações feminismo socialista, feminismo marxista e feminismo materialista são usadas de formas diversas, algumas vezes de maneira intercambiável, uma vez que as fronteiras entre elas são, com frequência, embaralhadas. Se se quiser fazer uma distinção, pode-se dizer que o feminismo socialista é uma designação que, no mundo anglófono, tem sido aplicada a um conjunto maior de teorias feministas do
}

\begin{tabular}{l|l}
42 & Funcionalista, determinista e reducionista:....
\end{tabular} 
teorias de sistemas duplos permitiram à teoria marxista das relações econômicas e sociais permanecerem basicamente inalteradas, uma vez que, assumindo-se que as categorias marxistas são cegas ao sexo, requereu-se apenas a adição de uma teoria das relações de gênero à teoria marxista. Por outro lado, a dificuldade do feminismo marxista (e do marxismo) em claramente identificar, em um nível teórico, a lógica subjacente da relação entre a opressão das mulheres e a dinâmica capitalista, favorece a afirmação de teorias de sistemas duplos ou triplos que reproduzem uma percepção fragmentada do mundo social.

O recurso às noções como a de modos de produção patriarcal e racial, ou ao modo de produção sexual-afetivo (FERGUSON, 1989), para explicar em nível sistêmico a persistência de diferentes formas de discriminação de gênero sob o capitalismo é equivalente a recorrer a um deus ex machina teórico ou a pressupor precisamente aquilo que precisa ser explicado - uma petição de princípio, portanto. Para mostrar os limites epistemológicos e teóricos de teorias de sistemas duplos ou triplos, abordarei aqui uma de suas versões mais sofisticadas, aquela elaborada por algumas autoras francesas que produziram um significativo trabalho teórico na linha do materialismo feminista. Com o objetivo de superar o reducionismo do modelo "base-superestrutura", por um lado, e os limites da teoria da interseccionalidade, por outro, o feminismo materialista recente deu particular atenção a interação recíproca entre as relações sociais. Danièle Kergoat (2009) e Jules Falquet (2009), por exemplo, sugeriram a necessidade de desenvolver uma teoria da "co-formação" ou da "consubstancialidade" de gênero, classe e raça. De acordo com essas autoras, a noção de interseccionalidade opera como um tipo de combinação geométrica de identidades que são

que apenas o feminismo marxista, incluindo também aquelas que desenvolveram uma teoria do patriarcado e tentaram combiná-la com a análise marxista do capitalismo. Ver Hennessy e Ingraham, 1997 e Gimenez, 2000. 
dadas antecipadamente e que tem a potencialidade de se multiplicarem infinitamente (DORLIN, 2005).

A perspectiva da consubstancialidade desenvolvida por Kergoat toma emprestada da interseccionalidade a ideia de interconexões recíprocas das relações de dominação e identitárias, mas tenta mostrar como essas relações continuamente se remodelam, marcamse e produzem umas às outras. Tenta, portanto, compreender essa interconexão como fortemente dinâmica e histórica. Ao fazê-lo, como Kergoat afirma, é possível se contrapor à distinção aguda entre as relações de classe que pertencem ao domínio econômico e as relações patriarcais que pertencem à esfera ideológica (KERGOAT, 2009, p. 118).

Entretanto, a tentativa de se contrapor a uma distinção aguda entre relações patriarcais, de raça e de classe através da noção de consubstancialidade parece ser problemática. Está baseada, na verdade, em algumas pressuposições controversas compartilhadas por muitas feministas materialistas. A primeira delas é que as relações de gênero, de classe e de raça são todas relações de produção: assim como as pessoas da Santíssima Trindade, na metáfora trinitária de Kergoat, elas não têm uma diferença de substância. A segunda pressuposição é que cada uma dessas relações é um sistema próprio, incluindo instâncias de exploração, dominação e opressão e, ademais, que juntas elas constituem um sistema unificado ou uma totalidade, por determinar mutuamente uma à outra. Pode-se encontrar uma abordagem semelhante na ideia de Christine Delphy de que as relações patriarcais devem ser entendidas como um modo de produção próprio, o modo patriarcal ou doméstico de produção, que tem autonomia frente ao capitalista, mas que, não obstante, interage simultaneamente com ele (DELPHY, 2009).

A noção de consubstancialidade tem o mérito de dar uma perspectiva dinâmica à maneira pela qual todas essas relações conjuntamente formam um sistema. Para usar uma metáfora, se, em seus inícios, a teoria da interseccionalidade pensava algumas vezes essa interação como geométrica ou mecânica, a teoria

\begin{tabular}{l|l}
\hline 44 & Funcionalista, determinista e reducionista:...
\end{tabular} 
da consubstancialidade, por sua vez, a pensa como uma interação semelhante à de uma reação de elementos químicos, combinando-se de forma a dar lugar a uma nova substância. Essa abordagem leva em conta e analisa a exploração de classe e atribui a ela um papel crucial. Mas a insistência na co-formação e consubstancialidade dessas relações sociais, animadas pela recusa a atribuir um papel determinante à exploração de classe, em um olhar mais detido, acaba reproduzindo um jogo incessante de relações. O que ela deixa de explicar é a lógica determinante de tal interação entre esses elementos químicos - isto é, o porquê, antes de tudo, esse tipo de interação ocorre. Na medida em que tudo determina tudo o mais, a noção de determinação perde sua função explicativa, e torna-se impossível evitar uma regressão infinita nas cadeias causais. Mais ainda, não é claro como a perspectiva da consubstancialidade pode escapar da multiplicação infinita de sistemas de opressão que ela condena na interseccionalidade.

Em um exame mais detido, estes desenvolvimentos das teorias de sistemas duplos ou triplos mostram os impasses teóricos fundamentais de tais teorias, mesmo em suas versões mais sofisticadas e historicamente fundamentadas. É válida, portanto, a tentativa de reavaliar uma teoria unitária, capaz de escapar do reducionismo e do determinismo. Com este objetivo em mente, no que se segue reexaminarei algumas das críticas contra tal abordagem unitária que foram colocadas no passado.

\section{Produção versus reprodução}

A apresentação da noção de reprodução das relações sociais, feita por Stevi Jackson em seu artigo Marxismo e Feminismo, pode servir como ilustração tanto de certos limites das maneiras em que a teoria foi elaborada, quanto das leituras equivocadas e caricaturizações às quais pode estar submetida. $\mathrm{O}$ artigo de Jackson tem como objetivo fornecer uma visão geral das interações entre marxismo e feminismo, do começo dos anos 1970 a meados dos anos 1990, e foi traduzido

cadernos cemarx, no $10-2017 \quad 45$ 
e publicado como a única entrada sobre marxismo e feminismo no Dictionnaire Marx contemporain, organizado por Jacques Bidet e Stathis Kouvelakis (2001). Essa visão geral é escrita a partir de uma perspectiva feminista materialista e tem um padrão implicitamente triádico, na qual a teoria marxista feminista é a tese, o feminismo pósestruturalista a antítese e o feminismo materialista a síntese. Dentro desse contexto geral, Jackson (1999, p. 19-20) apresenta a noção de reprodução das relações sociais nos seguintes termos:

esse foi um resultado lógico do $\mathrm{DLD}^{5}$, que produziu um tácito consenso no qual o trabalho doméstico continua a ser considerado como reprodução da força de trabalho; sugerir que ele produz algo tornou-se quase um tabu. Essa distinção entre produção e reprodução é espúria, sem sentido - algo não pode ser reproduzido sem ser primeiro produzido - e vai contra a posição de Marx de que todo processo de produção é, simultaneamente, um processo de reprodução [...]. Quando se diz que o trabalho das mulheres "reproduz" o proletariado ou as relações sociais capitalistas, a implicação é que elas fazem esse trabalho porque elas têm bebês. [...] Pode parecer bem curioso que feministas sucumbam a este flagrante determinismo biológico [...] mas esses são meios comuns do feminismo marxista teorizar a relação entre capitalismo e opressão das mulheres.

Dizer que essa passagem presta um desserviço a uma complexa discussão, por jogar com a ambiguidade semântica da palavra "produção", seria colocar as coisas de maneira branda. Como Jackson explicou algumas páginas antes, o núcleo do debate sobre o trabalho doméstico dizia respeito à discussão se ele produzia valor e mais-valor ou apenas valor de uso $^{6}$. A despeito de saber que a questão da produção de valor estava no centro do debate, Jackson surpreendentemente afirma que a distinção entre produção e reprodução não faz nenhum sentido, porque algo não pode ser reproduzido sem ser produzido

\footnotetext{
${ }^{5}$ Domestic Labor debate, ou Debate do Trabalho Doméstico [N.T.].

${ }^{6}$ Deixo de lado aqui o debate sobre os "benefícios": ver Holmstrom, 1981.
}

\begin{tabular}{l|l}
\hline 46 & Funcionalista, determinista e reducionista:...
\end{tabular} 
antes. Obviamente, essa afirmação se sustenta apenas se assumirmos a palavra "produção" em seu sentido geral, mas certamente não se mantém se o que queremos dizer é produção de valor. Ademais, as feministas marxistas e socialistas não negam que o trabalho de reprodução é um tipo de trabalho. Pelo contrário, as teóricas da reprodução social tendem a ampliar o conceito de trabalho necessário para incluir o trabalho reprodutivo em seu interior. Mas elas insistem que a forma social desse trabalho, e o conjunto específico de relações sociais no interior do qual ele se realiza (como, por exemplo, as relações de parentesco), pode ser distinguido teoricamente do trabalho formal remunerado.

Independentemente mesmo de uma interpretação de Marx, esta é uma importante diferença a ser ressaltada por motivos analíticos decisivos e muito importantes. Mas a leitura de Marx feita por Jackson não é menos intrigante: de fato, sua acusação da teoria como "espúria" é completamente sem fundamento, se se refere mesmo ao pensamento de Marx. A distinção entre produção e reprodução é claramente introduzida por ele, que não apenas aplicou o termo reprodução para designar fenômenos que vão da reprodução da força de trabalho à reprodução das classes, das relações de classe, das condições de produção e do capital mesmo (reprodução simples e ampliada), mas mais especificamente distinguiu o consumo individual (ou improdutivo) do consumo produtivo. $\mathrm{O}$ primeiro, o consumo individual, é crucial pra a reprodução do trabalhador, mas se realiza fora do processo produtivo (MARX, 1990, p. 717).

A menção à ideia de Marx de que "todo processo de produção é simultaneamente um processo de reprodução", provavelmente referese à passagem na qual Marx introduz a noção de reprodução simples no primeiro volume d'O Capital ${ }^{7}$ :

\footnotetext{
${ }^{7}$ A própria Jackson não oferece qualquer referência precisa.
} 
Seja qual for a forma social do processo de produção, ele deve ser contínuo, deve repetir periodicamente as mesmas fases. Uma sociedade não pode deixar de produzir, assim como não pode deixar de consumir. Quando visto, portanto, como um todo interconectado, e em um fluxo constante e incessante de renovação, todo processo social de produção é, ao mesmo tempo, um processo de reprodução (MARX, 1990, p. 711).

Mais tarde, Marx também insiste que ao produzir para o capitalista, o trabalhador está constantemente reproduzindo as relações de classe. Nesse sentido, o processo de produção também pode ser visto como um processo de reprodução (MARX, 1990, p. 716).

O significado dessas afirmações não é o de que existe uma perfeita identidade de produção e reprodução, nem de que é impossível distingui-las, e, certamente, não é o de que todo processo de reprodução é, ao mesmo tempo, um processo de produção de valor. Se produção refere-se à produção de valor, então enquanto todo processo de produção é, ao mesmo tempo, em certo sentido, um processo de reprodução, o contrário não é verdadeiro. O consumo, incluindo o consumo individual, consumo improdutivo, por exemplo, é uma parte fundamental do processo de reprodução de uma sociedade inteira. A primeira das passagens de Marx, citada acima, destaca o fato de que todo modo de produção deve constantemente reproduzir as condições de produção se a sociedade quer sobreviver: sob o capitalismo isso assume a forma da reprodução ampliada, devido à lógica da acumulação. Isso não significa que todo aspecto da reprodução das condições de produção produz valor. A burocracia estatal, a política, o controle policial, a família, a escola, a ciência, a tecnologia, a ideologia, etc. todas fazem parte da reprodução das condições de produção e de uma determinada formação social concreta, mas de acordo com Marx elas não são produção de valor.

Por outro lado, quando Marx refere-se ao fato de que, ao trabalhar para um capitalista, a trabalhadora reproduz tanto

48 Funcionalista, determinista e reducionista:... 
a si mesma enquanto trabalhadora como a relação de classe, substantivamente isso significa duas coisas: em primeiro lugar, uma vez que ela não possui os meios de produção, o trabalho assalariado é a única maneira através da qual a trabalhadora pode ter acesso aos meios necessários para sua própria reprodução e à de sua família. Em segundo lugar, o trabalho assalariado tem o traço característico de manter a trabalhadora em sua condição de expropriada sine die, devido à apropriação constante e repetida do mais-valor que ela produz, para não falar do processo de alienação social das capacidades dos trabalhadores, que são constantemente apropriadas e incorporadas ao capital fixo ${ }^{8}$. Ao trabalhar, a trabalhadora está constantemente reproduzindo o capital e as relações de classe capitalistas (MARX, 1990, p. 723-724). Mais ainda, ela não está apenas reproduzindo a si mesma como um ser humano genérico com necessidades e desejos, está se reproduzindo também enquanto trabalhadora, i.e., como uma membra de uma classe específica caracterizada pela expropriação e exploração e como um ser humano com alguns traços específicos, historicamente determinados e socialmente produzidos. Essa observação, mais uma vez, não implica que exista uma perfeita identidade entre produção e reprodução, de maneira que qualquer distinção seja "espúria e sem sentido". As relações de classe, assim como os seres humanos, certamente são reproduzidas dentro do processo de produção, mas não apenas dentro do processo de produção: há muitos aspectos da vida social que contribuem para sua reprodução e podem ser considerados como "produtivos" apenas se se empregar o termo de uma maneira vaga, não específica.

\section{Reprodução social e determinismo biológico}

De acordo com Jackson, a introdução do conceito de reprodução leva a uma confusão entre reprodução social, reprodução da força

${ }^{8}$ Ver Marx, 1990, p. 775-776. 
de trabalho e reprodução biológica, e tem como resultado final o determinismo biológico. Em 1980, Barrett publicou um livro que se tornou um clássico da literatura feminista socialista, Women's opression today, no qual ela criticava a noção de reprodução social por motivos bem semelhantes: a tendência de confundir o papel das mulheres na reprodução biológica da espécie com a questão, historicamente específica, de seus papeis na reprodução da força de trabalho masculina e na manutenção das relações de dominação e de subordinação da produção capitalista. Mais ainda, ela concluiu que o conceito de reprodução social, como elaborado até o momento, está tão intimamente ligado a uma perspectiva das relações de classe nas bases da produção capitalista que não pode ser considerado compatível com uma consideração séria da dominação masculina (BARRET, 1988, p. 29). Barrett observou que tentar "compreender o caráter da opressão da mulher no capitalismo contemporâneo em termos das supostas necessidades do capitalismo mesmo" é inadequado (BARRET, 1988, p. 248-249). Não é apenas funcionalista, mas também reducionista e não dá conta dos diferentes aspectos específicos da subordinação das mulheres. Ademais, corre o risco do determinismo biológico porque explica a opressão das mulheres dentro do capitalismo a partir de seu papel no lar como aquelas que dão à luz e são trabalhadoras domésticas, sem enxergar como esse papel é o resultado de dinâmicas sociais e de escolhas políticas, e não um produto inevitável da biologia.

A despeito do ceticismo de Barrett sobre a adequação da noção de reprodução social para a compreensão das características específicas da opressão das mulheres não fazer justiça ao potencial explicativo do conceito, algumas de suas críticas são justificadas. Em particular, ela está certa ao ressaltar que não se deve transformar a diferença sexual biológica em um deus ex machina explicativo, uma vez que é precisamente o significado social atribuído à diferença que deve ser explicado9 . Entretanto, a solução da própria Barrett para tal problema

\footnotetext{
${ }_{9}^{9}$ Ver, por exemplo, Benston, 1997 (publicado pela primeira vez em Monthly Review 21,

\begin{tabular}{l|l}
\hline 50 & Funcionalista, determinista e reducionista:...
\end{tabular}
} 
não é convincente. Em seu livro ela procura encontrar na ideologia a resposta para a questão do significado social atribuído à diferença sexual. Ela define ideologia como o termo genérico para processos através dos quais o significado é produzido, questionado, reproduzido e transformado. Esses processos estão sempre historicamente inseridos na prática material, desempenham um papel nas relações de produção e podem se tornar essenciais para a manutenção do sistema (BARRET, 1988). No caso do capitalismo, mais especificamente, a ideologia de gênero desempenha um papel significativo nas relações de produção, enquanto não tem qualquer papel essencial na reprodução de matérias primas, instalações e maquinaria: a relação do trabalho assalariado e as contradições entre trabalho e capital são "cegas ao sexo" e operam de maneira um tanto independente do gênero (BARRET, 1988, p. 99). O problema com essa posição é que, a despeito de poder evitar um determinismo biológico e um reducionismo econômico, ela, na verdade, não explica muito: dizer que a origem da atribuição de um significado social específico à diferença sexual é o processo através do qual este significado é produzido é uma tautologia, não uma explicação. Ademais, a ideia de que o capitalismo foi generificado por uma ideologia pré-existente não leva em conta que podese argumentar plausivelmente o oposto, isso é, que o processo de acumulação primitiva capitalista contribuiu para a criação de uma ideologia de gênero e de desigualdades de gênero de uma maneira fundamental ${ }^{10}$.

Antes de jogar o conceito de reprodução social na lata de lixo da história, vale a pena examinar se ele necessariamente implica o tipo de reducionismo e de determinismo biológico criticado por, entre outras, Jackson e Barrett. Se voltarmos à definição de Brenner e de Laslett de reprodução social, mencionada acima, o que parece evidente

4 (1969)

${ }^{10}$ Esta é, por exemplo, a tese de Silvia Federici em seu trabalho sobre a acumulação primitiva (Federici, 2004, p. 63-64). 
é que, para as duas autoras, a reprodução biológica é um fato central da vida humana, mas um fato que é sempre socialmente organizado e não pode ser considerado de maneira separada da reprodução social e societal. As relações de classe colocam as fronteiras no interior das quais a reprodução social ocorre e, portanto, no interior das quais a reprodução biológica também é organizada. Isso implica ainda que há processos de produção ideológica que atribuem significados específicos ao sexo, sexualidade, reprodução geracional, e diferença sexual. Como tal, a diferença biológica não indica nada mais do que o fato de que as mulheres dão à luz: isto, em si, não tem nenhum significado social ou cultural. Esses emergem porque o fato biológico da reprodução e da diferença sexual efetivam-se no interior de certos modos de reprodução societal e social que têm características específicas.

Pode-se encontrar um exemplo de uma aplicação histórica e empírica a essa perspectiva na crítica de Brenner e de Rama ao Women's opression today, de Barrett (BRENNER e RAMA, 1984). No artigo, elas oferecem uma explicação alternativa àquela oferecida por Barrett para a expulsão da mulher do trabalho assalariado na Grã-Bretanha entre 1840-1860, e para o surgimento, subsequente, de um mercado de trabalho segregado pelo sexo. De acordo com Barrett, a ideologia de gênero pré-existente desempenhou um papel decisivo ao empurrar os sindicatos de trabalhadores manuais masculinos a oporem-se ao trabalho feminino e forçar as mulheres à esfera doméstica. Dessa maneira o sistema doméstico foi implantado, o que moldou, então, o mercado de trabalho, empurrando-o na direção de uma divisão do trabalho generificada. $O$ ponto de partida de Brenner e Rama, ao contrário, é que por si só a ideologia de gênero pré-existente não poderia ter tal efeito. A ideologia pode, por exemplo, ter encorajado empregadores a pagar menos às mulheres, mas isso não ésuficiente para explicar porque elas estavam dispostas a aceitar salários mais baixos. A explicação para o afastamento das mulheres da produção industrial é que as exigências da reprodução biológica entraram em contradição material com o trabalho fabril industrial,

\begin{tabular}{l|l}
\hline 52 & Funcionalista, determinista e reducionista:...
\end{tabular} 
e com a maneira com que foi organizado nas circunstâncias históricas específicas de meados do século XIX, na Grã-Bretanha. O ponto não é que o fato biológico da reprodução era incompatível com a participação das mulheres na produção tout court, mas sim que ele não era facilmente compatível com a participação integral na produção capitalista pela maneira com que a produção era social e materialmente organizada em torno das necessidades do capital de maximizar sua apropriação de mais-valia. Essa contradição material explica porque um sistema doméstico específico efetivou-se.

Brenner e Ramas não negam o papel da ideologia nisso, mas elas destacam que a produção capitalista - e, portanto, uma certa estrutura de relações de classe - deram uma carga coerciva à reprodução biológica, o que explica porque a ideologia de gênero pôde proliferar. Pode-se concordar ou não com esse argumento, mas sua lógica não implica qualquer determinismo biológico. Pelo contrário, os limites colocados à reprodução biológica por relações de classe específicas e por uma organização específica do processo produtivo estão nas origens da subordinação da mulher: os fatos biológicos em si, apartados dessas relações, não explicam nada. Em suma, portanto, enquanto algumas autoras marxistas feministas podem ter caído em um determinismo biológico, a teoria da reprodução social, como tal, não é uma teoria biologicamente determinista. Ela dá atenção ao fato da reprodução biológica e ao papel diferencial que os sexos desempenham nela, não porque vê nisto a origem do significado social, mas pela maneira com a qual o capitalismo coloca limites e constrangimentos a eles, em outras palavras, pela maneira específica que a reprodução intergeracional é organizada no interior do capitalismo.

\section{Reprodução social e funcionalismo}

Em seu livro Barrett (1988, p. 138) acatou a impossibilidade de demonstrar a necessidade lógica da divisão sexual do trabalho. Contra a tentativa de demonstrar a funcionalidade para o capitalismo 
de todo fenômeno relacionado ao gênero, Barrett enfatizou a historicidade da intercalação entre divisão de gênero e capitalismo e indicou o caráter problemático e as contradições da relação entre gênero e classe. Entretanto, podemos nos questionar se ela estaria certa e se a única alternativa que temos é entre o funcionalismo, por um lado, e uma explicação das leis da produção capitalista como fundamentalmente cegas ao sexo e que seriam generificadas apenas como consequência de uma contingência histórica e da intervenção das ideologias de gênero advindas do passado, por outro. Essa última explicação, defendida por Barrett, atribui à ideologia o papel principal em generificar historicamente o capital, reproduzindo dessa maneira o dualismo que ela quer evitar. Mas, é verdade que indicar o papel constitutivo desempenhado pelas divisões de gênero dentro do processo de reprodução societal leva-nos a uma posição funcionalista na qual as tendências e contra-tendências, contradições e tensões são substituídas por leis de ferro infalíveis?

Nós certamente não precisamos aceitar um automatismo na reprodução da divisão sexual do trabalho, mais do que aceitaríamos um automatismo da reprodução da estrutura de classes como um todo. Dado que a reprodução das relações de produção é o terreno de uma luta em curso, uma perspectiva explicitamente assumida por Barrett em outra parte de seu livro, isso também se mantém para a divisão sexual do trabalho, mesmo no caso onde essa é considerada logicamente necessária para a reprodução das relações sociais capitalistas. Podemos até mesmo afirmar que se é verdadeiro que a divisão de gênero é logicamente necessária para o capitalismo ou, de outro modo, que é uma consequência lógica dele, a reprodução da estrutura de classe capitalista também depende do resultado da luta na divisão de gênero. Em outras palavras, conflitos e contradições permeiam todos os aspectos da reprodução das relações sociais capitalistas. Finalmente, o temor de Barrett do funcionalismo não leva em conta a flexibilidade fundamental do capitalismo, isto é, o fato de que as formas em que ocorre a reprodução social são historicamente variáveis e não estáticas,

54 $\quad$ Funcionalista, determinista e reducionista:... 
e que, mais uma vez, a agência coletiva daqueles que resistem, por exemplo, à privatização ou à mercadorização desempenha um papel crucial na negociação social sobre a maneira que a reprodução social é organizada.

A despeito da própria alternativa de Barrett ao funcionalismo não ser convincente, sua crítica à tendência do feminismo marxista ao funcionalismo não é inteiramente desprovida de fundamento. Ademais, Barrett não é, certamente, a única a avançar essa crítica. Em dois artigos sobre a reprodução, Sue Ferguson indica que as feministas da reprodução social não conseguiram superar o funcionalismo herdado do marxismo estruturalista (FERGUSON, 1999; FERGUSON, 2008). Ela argumenta que conseguiram superar o reducionismo econômico ao ampliar o conceito de economia e entende-lo como um sistema através do qual as pessoas se organizam para satisfazer as necessidades humanas. Mais ainda, elas evitaram tomar o marxismo como uma ciência abstrata que oferece apenas as "leis do movimento econômico". Pelo contrário, assumiram "o projeto do materialismo histórico de desconstruir as relações sociais que tornam essas leis possíveis" (FERGUSON, 1999, p. 7). Entretanto, continuaram a recorrer a alguns conceitos teóricos básicos que retomam a abordagem estrutural funcionalista típica das teorias dos sistemas duplos. Isso parece evidente, por exemplo, em conceitos como o da correlação de "leis demográficas" e "leis econômicas", ou na tendência a tratar a economia como uma "coisa", ou como uma estrutura, e não como um conjunto vivo de relações sociais, que são historicamente mutáveis e que são produto das práticas das pessoas (FERGUSON, 2008, p. 46). De acordo com Ferguson, o limite dessa abordagem é que ela conceitua o capitalismo como um conjunto de estruturas no interior do qual as pessoas agem funcionalmente de maneiras prescritas.

Uma perspectiva mais interessante é aquela oferecida mais recentemente por Bakker e Gill que, contra as "noções reificadas de estrutura ou de agência", insistiram no fato de que, para compreendermos como uma formação social reproduz a si mesma, 
precisamos analisar as relações sociais de produção e a mediação e transformação dessas relações através da atividade intencional conjuntamente com o papel da subjetividade humana, que também inclui a forma que essa subjetividade é constituída através da classe, do gênero, da racialização, da sexualidade, e assim por diante. Esses não são diferentes níveis ou estruturas, relacionando-se umas com as outras de uma maneira externa, mas diferentes momentos de uma unidade contraditória (BAKKER e GILL, 2003).

Concluindo, o funcionalismo não é uma fraqueza intrínseca ao conceito de reprodução social, mas sim o resultado da dificuldade que os feminismos socialista e marxista tiveram em articular a reprodução social em uma teoria consistente. Identificar esses limites na literatura produzida até aqui, portanto, é um primeiro passo necessário para liberar as potencialidades da noção de reprodução social.

\section{Conclusão: reprodução social recarregada}

O objetivo desse artigo foi mostrar que o conceito de reprodução social como tal não implica quaisquer das debilidades teóricas atribuídas por seus críticos, visto que tem um enorme potencial explicativo. Ademais, frequentemente aqueles que o criticaram não foram capazes de oferecer uma alternativa sólida e acabaram em impasses teóricos ainda maiores, exemplificados particularmente pelas teorias dos sistemas duplos e triplos. A noção de reprodução social tem o potencial de evitar esse impasse, enquanto, concomitantemente, propõe uma explicação não-reducionista do modo capitalista de produção, onde o capital não é visto como o sujeito de um processo estritamente "econômico". Como Danel Bensaïd (2001, p. 47-48) coloca:

em Marx, o capital é o sujeito de um processo que não é estritamente "econômico". Ele articula os processos de produção, circulação (e, portanto, de distribuição) e da reprodução total.

56 Funcionalista, determinista e reducionista:... 
A "crítica da economia política" é, em primeiro lugar, uma crítica do fetichismo econômico e de sua ideologia, que nos condena a pensar "sob a sombra do capital".

Uma teoria unitária da reprodução social implicaria a compreensão da abrangente lógica da acumulação ampliada capitalista de uma maneira que é substancialmente diferente de uma lei mecânica. O capital, de fato, não é uma máquina. Enquanto o automatismo é um dos traços do processo de auto-valorização do valor, o entendimento do processo de reprodução do capitalismo não pode estar simplesmente apoiado em uma compreensão de seus aspectos automáticos. Esses, de fato, são constantemente combinados com a agência humana e com a agência de classe dentro do processo de reprodução total, de maneira que perder de vista um desses aspectos leva a uma compreensão muito empobrecida do funcionamento fundamental da acumulação ampliada capitalista.

\section{Referências bibliográficas}

BARRETT, M. [1980]. Women's Oppression Today. The Marxist/Feminist Encounter. Londres: Verso, 1988.

e MCINTOSH, M. Christine Delphy: Towards Materialist Feminism. Feminist Review, v. 1, 1979, p. 95-106.

BENSAÏD, D. Les irréductibles. Théorèmes de la résistance à l'air du temps. Paris: Textuel, 2001.

BENSTON, M. [1969]. The Political Economy of Women's Liberation. In: HENESSY, R. e INGRAHAM, C. Materialist Feminism. A Reader in Class, Difference and Women's Lives. Londres: Routledge, 1997. 
BAKKER, I. e GILL, S. Ontology, Method and Hypotheses. In: BAKKER, I. e GILL, S. Power, Production and Social Reproduction. Basingstoke: Palgrave MacMillan, 2003.

BIDET, J. e KOUVÉLAKIS, E. Dictionnaire Marx Contemporain. Paris: Puf, 2001.

BRENNER, J. e LASLETT, B. Gender and Social Reproduction: Historical Perspectives. Annual Review of Sociology v. 15, 1989, p. 381-404.

Social Reproduction, and Women's Self-Organization: Considering the US Welfare State. Gender \& Society, v. 5, n. 3, 1991, p. 311-333.

e RAMAS, M. Rethinking Women's Oppression. Discussion of Michèle Barrett's Women's Oppression Today. New Left Review, I/144, mar-abr.1984, p. 33-71.

BEZANSON, K. e LUXTON, M. Social Reproduction: Feminist Political Economy Challenges Neoliberalism. Montreal: McGill-Queen's University Press, 2006.

DELPHY, C. L'Ennemi principal. 1. Économie politique du patriarcat. Paris: Éditions Syllepse, 2009.

DORLIN, E. De l'usage épistémologique et politique des categories de «sexe» et de «race» dans les études sur le genre. Cahiers du genre, n. 39,2005 , p. 83-105.

FALQUET, J. La règle du jeu. Repenser la co-formation des rapports sociaux de sexe, de classe et de «race». In: DORLIN, E. Sexe, race et classe. Paris: PUF, 2009.

58 Funcionalista, determinista e reducionista:... 
FEDERICI, S. Caliban and the Witch. Women, the Body and Primitive Accumulation. Brooklyn: Autonomedia, 2004.

FERGUSON, A. Blood at the Root. Motherhood, Sexuality \& Male Dominance. Londres: Pandora, 1989.

FERGUSON, S. Building on the Strengths of the Socialist Feminist Tradition. In: Critical Sociology, vol. 25, n. 1, jan. 1999, p. 1-15.

Canadian Contributions to Social Reproduction Feminism, Race and Embodied Labor. Race, Gender \& Class, v. 15, n. 1-2, 2008, p. 42-57.

GIMENEZ, M. What's Material about Materialist Feminism? A Marxist Feminist Critique. Radical Philosophy, n. 101, p. 18-28, mai-jun. 2000.

. Capitalism and the Oppression of Women: Marx Revisited. Science and Society, v. 69, n. 1, jan. 2005, p. 11-32.

HARTMANN, H. The Unhappy Marriage of Marxism and Feminism: Towards a More Progressive Union. In: SARGENT, L. Women and Revolution: a Discussion of the Unhappy Marriage of Marxism and Feminism. Boston: South End Press, 1981.

HENNESSY, R. e INGRAHAM, C. Introduction. Reclaiming Anticapitalist Feminism. In: _. Materialist Feminism. A Reader in Class, Difference, and Women's Lives. Londres: Routledge, 1997.

HOLMSTROM, N. 'Women's Work', the Family and Capitalism. Science and Society, v. 45, n. 2, verão 1981, p. 186-211.

cadernos cemarx, $\mathrm{n}^{\mathbf{0}} 10-2017 \quad 59$ 
JACKSON, S. Marxism and Feminism. In: GAMBLE, A.; MARSH, D.; TANT, T. Marxism and Social Science. Chicago: University of Illinois Press, 1999.

KATZ, C. Growing Up Global: Economic Restructuring and Children's Everyday Lives. Minneapolis: University of Minnesota Press, 2004.

KERGOAT, D. Dynamique et consubstantialité des rapports sociaux. In: DORLIN, E. Sexe, race et classe. Pour une épistémologie de la domination. Paris: PUF, 2009.

MARX, K. Capital, Volume 1. Londres: Penguin Books, 1990. . Capital, Volume II. Londres: Penguin Books, 1992. . Grundrisse. Londres: Penguin Books, 1993.

ROSENEIL, S. Gender. In: HARALAMBOS, M. e HOLBORN, M. Developments in Sociology. Ormskirk: Causeway Press, 1994.

WALBY, S. Theorizing Patriarchy. Cambridge: Basil Blackwell, 1990.

YOUNG, I. M. [1980]. Socialist Feminism and the Limits of Dual Systems Theory. In: HENNESSY, R. e INGRAHAM, C. Materialist Feminism. A Reader in Class, Difference and Women's Lives. Londres: Routledge, 1997.

VOGEL, L. Marxism and the Oppression of Women. Toward a Unitary Theory. Nova Jersey: Rutgers University Press, 1983.

\begin{tabular}{l|l}
\hline 60 & Funcionalista, determinista e reducionista:...
\end{tabular} 